\title{
Is There Effect of Murottal Therapy? Pregnancy Response with Spiritual Islamic Nursing Care Application
}

\author{
Apakah Ada Efek dari Terapi Murottal? \\ Respon Kehamilan dengan Aplikasi Spiritual Islamic Nursing Care \\ Nur Hidayah*1 ${ }^{1}$ Kristan Kristan ${ }^{2}$, Ika Kartina ${ }^{3}$, Muslimin Ardi $^{4}$ \\ ${ }^{1,3,4}$ Bagian Keperawatan, Universitas Islam Negeri Alauddin Makassar, Makassar \\ ${ }^{2}$ Bagian Computer Science, Bina Nusantara University, Jakarta
}

DOI: 10.24252/al-sihah.v13i2.24991

Received: 14 November 2021 / In Reviewed: 4 December 2021 / Accepted: 30 December 2021 / Available online: 31 December 2021 CThe Authors 2021. This is an open access article under the CC BY-NC-SA 4.0 license

\begin{abstract}
The Spiritual Islamic Nursing Care (SINC) application is an innovation in spiritual services that has a murottal feature that can be used to reduce anxiety responses in patients. This application is used to help mothers with gestational age entering the period of seven months or third trimester who experience anxiety and irregular fetal heartbeat in primigravida mothers. The purpose of this study was to examine the effect of murottal therapy with the application of Spiritual Islamic Nursing Care (SINC) on the response of the third trimester of pregnancy. The research design used a quasi-experiment with a one-group pre and post-test design approach. The sample in this study amounted to 10 respondents using the accidental sampling technique. Data were collected using Doppler to measure the fetal heart rate (FHR), visual fetal movement, and the DASS (Depression Anxiety Stress Scale) questionnaire to measure the level of anxiety in pregnant women. Analysis of the data used was the Friedman test for fetal movement and fetal heart rate and the Wilcoxon test for the anxiety level of pregnant women. After the research, the results of statistical tests showed that there was a significant difference in the fetal heart rate and the anxiety level of the third trimester pregnant women before and after being given murottal therapy with the application of Spiritual Islamic Nursing Care (SINC). Therapy using murottal with the Spiritual Islamic Nursing Care (SINC) application provides recommendations that can be used in various health services for pregnant women.
\end{abstract}

\begin{abstract}
ABSTRAK
Aplikasi Spiritual Islamic Nursing Care (SINC) adalah inovasi dalam pelayanan spiritual yang memiliki fitur murottal yang dapat digunakan dalam menurunkan respon kecemasan pada pasien. Aplikasi ini digunakan untuk membantu ibu dengan usia kehamilan memasuki periode tujuh bulan atau trimester ketiga yang mengalami kecemasan dan denyut jantung janin tidak teratur pada ibu primigravida. Penelitian ini bertujuan untuk menganalisis pengaruh terapi murottal dengan aplikasi Spiritual Islamic Nursing Care (SINC) terhadap respon kehamilan trimester tiga. Desain penelitian menggunakan metode quasi eksperimen dengan pendekatan one group pre and post test design. Sampel pada penelitian ini berjumlah 10 responden dengan menggunakan teknik accidental sampling. Pengambilan data dikumpulkan menggunakan Doppler untuk mengukur secara visual denyut jantung janin (DJJ), gerakan janin secara visual dan kuesioner DASS (Depression Anxiety Stress Scale) untuk mengukur tingkat kecemasan pada ibu hamil. Analisa data yang digunakan yaitu uji Friedman untuk pergerakan janin dan denyut jantung janin dan uji Wilcoxon untuk tingkat kecemasan ibu hamil. Setelah dilakukan penelitian hasil uji statistis menunjukkan bahwa ada perbedaan signifikan denyut jantung janin dan tingkat kecemasan ibu hamil trimester III sebelum dan sesudah diberikan terapi murottal dengan penerapan aplikasi Spiritual Islamic Nursing Care (SINC). Terapi menggunakan murottal dengan aplikasi Spiritual Islamic Nursing Care (SINC) memberikan rekomendasi yang dapat digunakan di berbagai pelayanan kesehatan ibu hamil.
\end{abstract}

\section{GRAPHICAL ABSTRACT}

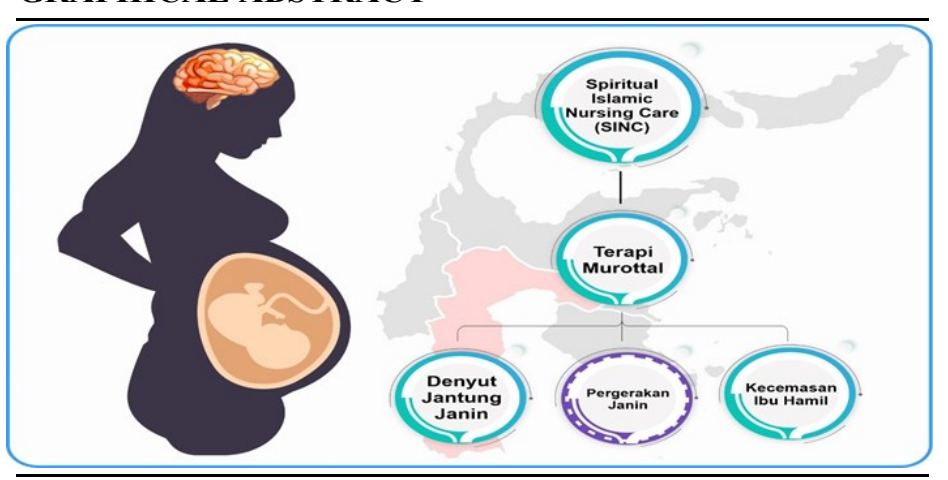

Keyword

anxiety of pregnant women; fetal heart rate; murottal therapy; spiritual islamic nursing care application

\section{Kata Kunci:}

aplikasi spiritual islamic nursing care, denyut jantung janin; kecemasan ibu hamil; terapi murottal

* Correspondence

Jl. Sultan Alauddin No.63 Mangasa, Kec. Tamalate, Kota Makassar, 90221

Email: nur.hidayah@uin-alauddin.ac.id 


\section{PENDAHULUAN}

Kehamilan adalah proses alami bagi setiap wanita usia subur. Selama kehamilan, terjadi perubahan fisiologis dapat dialami pada ibu hamil. Rasa tidak nyaman pada payudara, mual, muntah, nyeri tekan pada vulva, distensi abdomen, dan berhentinya menstruasi merupakan perubahan fisiologis (Talbot \& Maclennan, 2016; Soma-Pillay et al., 2016). Perubahan psikologis seperti perasaan bahwa kehamilan dapat hadir ketika ibu akan terus memikirkan situasi dan keselamatan bayinya, dan terkadang ibu akan menjadi lebih sadar akan keselamatan bayinya dan dirinya sendiri (Brunton et al., 2021; McLeish \& Redshaw, 2017).

Kehamilan dibagi menjadi tiga bagian, yaitu trimester pertama (0-12 minggu), trimester kedua (12-18 minggu) dan trimester ketiga (28-40 minggu) dari usia kehamilan. Pada trimester ketiga, volatilitas emosional kembali. Pada saat yang sama, ada perasaan ketidaknyamanan fisik. Fokusnya juga berubah meskipun pada masalah keuangan, seperti menyiapkan kamar bayi, perlengkapan anak, pengaruh dan kemampuan orang tua. Dengan demikian, perubahan ini berisiko menimbulkan reaksi psikologis mulai dari gangguan emosional ringan hingga psikosis berat (Dahro, 2012). Menurutnya, kecemasan adalah reaksi fisik, mental, dan kimia tubuh terhadap situasi yang menakutkan, mengejutkan, membingungkan, berbahaya, dan mengganggu. Reaksi ini terjadi pada banyak orang. Tingkat gangguan kecemasan hingga 21\%-43\% (Zamriati et al., 2013).

Prevalensi tingkat kecemasan ibu hamil di berbagai negara didunia yaitu kecemasan ibu hamil di china $(26 \%$ $34.2 \%$ ), Inggris $(20 \%)$, belgia $(40 \%)$ dan Canada mencapai (57\%) (Cameron et al., 2020). Sementara di indonesia, kecemasan pada ibu hamil di indonesia mencapai 373.000.000. sebanyak 107.000.000 atau $28.7 \%$ diantaranya kecemasan terjadi pada ibu hamil menjelang proses persalinan (Kementerian Kesehatan RI, 2017). Sebuah penelitian yang dilakukan pada ibu primigravida $22,5 \%$ mengalami cemas ringan, $30 \%$ mengalami cemas sedang, $27,5 \%$ cemas berat, dan $28 \%$ mengalami cemas sangat berat.

Angka kematian ibu (AKI) di Indonesia nyatanya masih sangat tinggi yaitu mencapai 305/100.000 kelahiran hidup (KH) berdasarkan hasil Survei Demografi Antar Sensus (SUPAS) tahun 2015. Namun, tahun 2012 kembali menyaksikan peningkatan yang sangat cepat yaitu 359/100.000 KH (Kementerian Kesehatan RI, 2014). Ada beberapa penyebab utama kematian ibu diantaranya perdarahan, infeksi, partus lama/macet, aborsi dan hipertensi dalam kehamilan (Lawson \& Keirse). Di Indonesia, kematian ibu didominasi oleh tiga penyebab utama. yaitu, perdarahan $20 \%$, infeksi 31\% dan hipertensi dalam kehamilan (HDK) 32\%. menjadi 5 kematian ibu dari 20.181 kelahiran hidup di kota Makassar. Penyebab kematian ibu di Makassar ada tiga yaitu perdarahan, preeklamsia ringan dan preeklampsia berat (Dinas Kesehatan Kota Makassar, 2015).

Berbagai tempo musik mempunyai efek fisiologis pada tubuh, salah satu efeknya adalah mempengaruhi denyut jantung dan tekanan darah sesuai frekuensi, 
tempo, dan volumenya C. Jantung cenderung mengikuti dan mencoba menyamai tempo suatu bunyi (Liu \& Petrini, 2015; Koelsch \& Jäncke, 2015; Veternik et al., 2018). Volume yang bisa menimbulkan efek teraupetik adalah 40-60 dB (Im-Oun, et al., 2018). Sedangkan waktu yang dibutuhkan dalam auditoris therapy (terapi pendengaran) supaya dapat memberikan efek terapeutik adalah minimal 10 menit (Thoma et al., 2015). Senada dengan penelitian Wahyuni \& Deswita (2013) bahwa terapi murottal Al-Qur'an dapat dijadikan sebagai penyembuh sakit. Telah dibuktikan dan dilakukan oleh orang yang membaca Al-Qur'an atau mendengarkannya akan memberikan perubahan arus listrik di otot, perubahan sirkulasi darah, perubahan detak jantung dan perubahan kadar darah pada kulit. Al-Qur'an dapat membantu mengurangi penderitaan dan stres manusia, mendengarkan Al-Qur'an dapat digunakan untuk mengembangkan kesehatan mental yang baik dan mencapai lebih banyak kedamaian dalam pengobatan islam, AlQur'an sering digunakan untuk meningkatkan kesehatan dan menyembuhkan penderita stres dan gangguan psikologis (Priyanto et al., 2020; Mahjoob et al., 2014). Terapi murottala Al-Qur'an atau tilawah Al-Qur'an dengan irama teratur dan tajwid yang tepat juga merupakan musik Al -Qur'an yang memiliki kemampuan untuk membawa ketenangan dan mengurangi kecemasan (Adhiwijaya et al., 2021; Lismayanti et al., 2020; Ghofar \& Ningsih, 2012).

Organisasi Kesehatan Dunia sebenarnya telah merekomendasikan nega- ra-negara Muslim untuk menyediakan buku -buku yang berisi ayat-ayat Al-Qur'an yang berkaitan dengan kesehatan mental. Keputusan ini dibuat pada KTT Regional tentang Kesehatan Mental yang diadakan di Mediterania Timur pada tahun 1998 (Mottaghi et al., 2011). Dalam penelitian yang dilakukan oleh Jabbari et al. (2017) menunjukkan hasil penelitian hanya dengan atau tanpa terjemahan, keduanya yang efektif untuk mengurangi stres, kecemasan dan depresi selama intensitas nyeri kehamilan. Selain itu Azis et al. (2015) menggunakan surah Ar-Rahman terhadap pasien persalinan dan mendapatkan pengaruh terjadinya penurunan intensitas nyeri dan peningkatan kadar $\beta$ - Endorphin. Berdasarkan fenomena tersebut, peneliti melakukan penelitian yang bertujuan untuk melihat adanya pengaruh terapi murottal menggunakan aplikasi Spiritual Islamic Nursing Care (SINC) untuk mengamati respon kehamilan trimester III pada denyut jantung janin, gerakan bayi dan kecemasan ibu.

\section{METODE PENELITIAN}

Penelitian ini menggunakan metode kuantitatif dengan desain penelitian quasi eksperimen dengan pendekatan one group pre and post test design. Metode ini bertujuan untuk mengetahui pengaruh terapi murottal dengan aplikasi Spiritual Islamic Nursing Care (SINC) pada respon kehamilan trimester III. Respon kehamilan yang dimaksud adalah pergerakan janin, denyut jantung janin dan tingkat kecemasan ibu hamil. Populasi dalam penelitian ini adalah seluruh ibu hamil primigravida trimester III 
Tabel 1

Distribusi Frekuensi Responden

\begin{tabular}{ccccc}
\hline Variabel & Rerata & Median & Std. Deviasi & Min-Maks \\
\hline DJJ Pre & 135.10 & 137 & 6,577 & $127-147$ \\
DJJ Post & 131.30 & 131.5 & 5,889 & $124-143$ \\
Pergerakan Janin Pre & 4.40 & 4 & 2,066 & $2-9$ \\
Pergerakan Janin Post & 5.20 & 5 & 1,989 & $3-10$ \\
Tingkat Kecemasan Pre & 13.90 & 14.5 & 3,573 & $8-19$ \\
Tingkat Kecemasan Post & 12.00 & 12 & 2,677 & $7-15$ \\
\hline
\end{tabular}

yang berada di wilayah kerja Puskesmas Kassi-Kassi Makassar yaitu sebanyak 41 responden. Sampel dalam penelitian ini adalah 10 ibu hamil primigravida yang yang memenuhi kriteria inklusi.Teknik penyampelan dalam penelitian ini adalah purposive yaitu mengambil sampel yang sesuai dengan kriteria inklusi berjumlah 10 orang. Dalam penelitian ini instrumen yang digunakan berupa doppler untuk mengukur denyut jantung janin dan kuesioner yang berisikan pertanyaan-pertanyaan yang akan dijawab oleh responden/sampel. Kuesioner yang digunakan adalah kuesioner baku DASS (Depression Anxiety Stress Scale) yang terdiri dari 14 butir pertanyaan berdasarkan gejala subjektif yang dirasakan responden mengenai kecemasan. Uji statistik yang akan digunakan adalah uji wilcoxon untuk tingkat kecemasan dan uji friedman untuk pergerakan janin dan denyut jantung janin.

\section{HASIL PENELITIAN}

Berdasarkan Tabel 1 menunjukkan rerata distribusi frekuensi DJJ ibu hamil trimester II kehamilan di wilayah kerja Puskesmas Kassi-Kassi Makassar sebelum intervensi mendapat nilai rerata 135.10 , sedangkan median (min-maks) adalah 137 (127-147), dengan standar deviasi 6,577. .
Setelah dilakukan intervensi, rata-rata distribusi frekuensi DJJ ibu hamil trimester II memiliki nilai mean 131,30 , nilai median (min-maks) 131,5 (124-143), dengan pola error terutama 5.889. Sementara itu, ratarata distribusi frekuensi gerakan janin sebelum prosedur memiliki nilai rata-rata 4,40, sedangkan nilai (min-maks) adalah 4 (2-9), dengan standar deviasi 2,066. Distribusi frekuensi rata-rata gerakan janin setelah prosedur memiliki rata-rata 5,20, sedangkan rata-rata (min-maks) adalah 5 (3-10) dengan standar deviasi 1989. Untuk distribusi frekuensi tingkat kecemasan ibu hamil. Pada wanita trimester ketiga sebelum intervensi, mean adalah 13,90, sedangkan median (min -maks) adalah 14,5 (8-19) dengan standar deviasi 3,573. Setelah dilakukan intervensi, distribusi frekuensi tingkat kecemasan ibu hamil pada kehamilan trimester II memiliki nilai rerata 12,00 , sedangkan nilai median (min-maks) adalah 12 (7-15), dengan sebaran 2,677.

Berdasarkan hasil Tabel 2 hasil uji statistik yang telah dilakukan dengan menggunakan uji Wilcoxon diperoleh nilai $p$ -value untuk tingkat kecemasan ibu hamil diperoleh nilai sebesar 0,046 . Secara statistik jika nilai $\mathrm{p}>0,05$ maka Ha ditolak dan apabila nilai $\mathrm{p}<0,05$ maka Ha diterima. Oleh karena itu, berdasarkan hasil analisis 
Tabel 2

Pengaruh Terapi Murottal dengan Aplikasi SINC pada Tingkat Kecemasan Ibu Hamil

\begin{tabular}{lcc}
\hline \multicolumn{1}{c}{ Variabel } & Z-test & $p$ value \\
\hline Tingkat Kecemasan Pre & $-2,000$ & 0,046 \\
Tingkat Kecemasan Post & & \\
\hline
\end{tabular}

dapat disimpulkan bahwa terapi murottal dengan penerapan Spiritual Islamic Nursing Care (SINC) berpengaruh terhadap tingkat kecemasan ibu hamil primigravida trimester III di wilayah kerja Puskesmas Kassi-kassi Makassar.

Berdasarkan Tabel 3 hasil uji statistik dilakukan dengan menggunakan uji Friedman diperoleh nilai $p$ value untuk pergerakan janin 0,236 . Hal ini berarti nilai $\mathrm{p}>0,05$ sehingga tidak ada pengaruh terapi murottal dengan aplikasi Spiritual Islamic Nursing Care (SINC) terhadap pergerakan janin. Sedangkan untuk denyut jantung janin (DJJ) setelah dilakukan uji statistik diperoleh nilai $p$ value sebesar 0,000 . Nilai p diperoleh sebesar $<0,05$, sehingga dapat disimpulkan bahwa terapi murottal dengan penerapan aplikasi Spiritual Islamic Nursing Care (SINC) berpengaruh yang berarti terhadap denyut jantung janin (DJJ) pada ibu hamil primigravida trimester III.

\section{PEMBAHASAN}

\section{Pergerakan Janin}

Hasil uji statistik yang dilakukan didapatkan bahwa terapi dengan menerapkan aplikasi SINC tidak berpengaruh terhadap pergerakan janin ibu hamil trimester III di wilayah kerja kerja Puskesmas Kassikassi Makassar. Menurut peneliti, hal ini dikarenakan rata-rata gerakan janin ibu hamil pada trimester ketiga masih dalam batas normal yaitu minimal 1 gerakan setiap 15 menit saat janin tidak dalam keadaan istirahat.

The American Congress of Obstetricians and Gynecologists (ACOG) merekomendasikan ibu hamil yang memasuki minggu ke-28 mengalami sedikitnya 10 gerakan janin baik berupa tendangan, lunges, maupun spin. Idealnya, Ibu hamil akan merasakan setidaknya 10 gerakan janin dalam 2 jam. Menurut penelitian Fatmawati (2013) menunjukkan bahwa ketika janin diperdengarkan dengan terapi murottal maka janin akan merespon dengan mendengarkannya dengan tenang tanpa banyak bergerak.

\section{Denyut Jantung Janin}

Pemberian stimulasi murottal tidak hanya bermakna bagi ibu hamil tetapi juga bagi janin yang dikandungnya. Denyut jantung janin (DJJ) sebelum dan sesudah intervensi terapi murottal dengan menggunakan aplikasi SINC tetap dalam kisaran normal dari 120x/menit hingga 160x/menit dengan jumlah responden hingga $100 \%$. Berdasarkan uji statistik yang dilakukan didapatkan bahwa terdapat perbedaan denyut jantung janin pada ibu hamil yang mendapat terapi dilatasi dibandingkan dengan ibu hamil yang tidak mendapat terapi dilatasi. Berdasarkan hasil Kajian diketahui bahwa ibu hamil yang 
Tabel 3

Pengaruh Terapi Murottal dengan Aplikasi SINC pada Pergerakan Janin dan Denyut Jantung Janin

\begin{tabular}{lcccc}
\hline \multicolumn{1}{c}{ Variabel } & $\mathrm{n}$ & Chi-square & df & $p$ value \\
\hline $\begin{array}{l}\text { Pergerakan Janin Pre } \\
\text { Pergerakan Janin Post }\end{array}$ & 10 & 81,782 & 13 & 0,233 \\
$\begin{array}{l}\text { Denyut Jantung Janin (DJJ) Pre } \\
\text { Denyut Jantung Janin (DJJ) Post }\end{array}$ & 10 & 16,315 & 13 & 0,000 \\
\hline
\end{tabular}

mendapat terapi murottal dan ibu hamil yang tidak mendapat terapi murottal memiliki denyut jantung janin (FHR) yang lebih lambat, denyut jantung janin teratur, meskipun masih dalam batas normal. jangkauan. Terapi 1 murottal dengan aplikasi SINC berpengaruh terhadap denyut jantung janin (DJJ) pada ibu hamil trimester III di wilayah kerja Puskesmas Kassi-kassi. Hal ini sejalan dengan penelitian Mukhlis \& Marini (2020) menunjukkan bahwa dengan mendengarkan terapi murottal dapat meningkatkan denyut jantung bayi. Berdasarkan penelitian Fatmawati (2013) bahwasanya denyut jantung janin sangat dipengaruhi oleh intonasi bunyi/suara, dimana intonasi yang lembut atau yang mirip dengan suara ibu membuat suasana menjadi lebih tenang dan detak jantung janin relatif stabil.

Sistem saraf otonom terdiri dari sistem saraf simpatik dan parasimpatis yang merupakan faktor yang mempengaruhi fungsi jantung. Ketika jumlah oksigen di jantung normal, maka akan menghasilkan suara jantung dasar yang berbeda dari jantung janin normal. Bila cadangan nutrisi plasenta cukup, maka akan menyebabkan peningkatan cepat bunyi jantung janin. Kelainan irama jantung janin berupa takikardia atau rakhitis dapat terjadi pada janin (Nugroho, et al., 2014).
Pemenuhan kebutuhan oksigen ibu untuk janin dapat dicapai dengan olahraga teratur. Karena saat berolahraga, jantung dapat memompa lebih baik dan akan mendistribusikan lebih banyak oksigen ke seluruh tubuh, termasuk janin. Ada beberapa jenis olahraga yang bisa dilakukan oleh ibu hamil, namun olahraga yang aman dan untuk ibu hamil antara lain jalan kaki, berenang, sepeda statis, dan olahraga untuk ibu hamil (Melzer et al., 2010; Kader \& NaimShuchana, 2014).

Bagi ibu hamil, olahraga juga membawa banyak manfaat. Penelitian yang dilakukan oleh May et al. (2016) menunjukkan bahwa ketika ibu hamil aktif secara fisik/ olahraga, janin mendapat efek membuat jantung bayi lebih sehat. Setidaknya detak jantungnya tidak cepat, tapi lambat. Jantung akan menjadi lebih kuat jika berolahraga, dan jika jantung sehat maka detak jantung akan menurun. Jadi jantung tidak harus bekerja keras untuk memompa darah dalam jumlah yang sama.

\section{Tingkat Kecemasan Ibu}

Tingkat kecemasan ibu hamil setelah mendapat intervensi terapi murottal dengan aplikasi SINC menurun dari 5 (50\%) dengan kecemasan berat menjadi 2 orang (20\%). Dan sebagian besar responden mengalami tingkat kecemasan sedang setelah 
dilakukan intervensi. Setelah dilakukan uji statistik didapatkan bahwa terapi murottal dengan penerapan aplikasi SINC berpengaruh terhadap tingkat kecemasan ibu hamil trimester III. Hal ini sejalan dengan penelitian yang telah dilakukan oleh Jabbari et al. (2017) menunjukkan bahwa dengan atau tanpa terjemahan keduanya samasama efektif dalam mengurangi stres, kecemasan, dan depresi selama masa kehamilan. Menurut penelitian Budiyarti \& Makiah (2018) terapi murottal dapat menurunkan tingkat kecemasan ibu hamil primigravida trimester 3. Hal ini dijelaskan pada Penelitian Irmawati et al. (2020) yang menjelaskan bahwa dengan mendengarkan bacaan Al-Qur'an khususnya surah ArRahman dapat mengurangi kecemasan pada ibu hamil dalam menghadapi proses persalinan. Hal ini juga sejalan dengan penelitian yang dilakukan yang menyimpulkan Ria et al. (2019) bahwa murottal Al -Qur'an dapat mengurangi rasa sakit dan kecemasan pada ibu bersalin saat fase aktif.

Membaca ayat suci Al-Qur'an memiliki efek langsung dalam mengurangi kecemasan, kegelisahan dan bahkan depresi, secara langsung atau tidak langsung memiliki efek stimulasi pada sistem kekebalan tubuh yang mendukung proses penyembuhan. Penjelasan-penjelasan tentang kebaikan-kebaikan yang terkandung dalam Al-Qur'an dapat menjadi motivator yang hebat bagi mereka yang membaca atau mendengarkannya. Keyakinan akan kebenaran Al-Qur'an dapat menjadi faktor penting dalam membuat orang merasa tenang dalam diri mereka, termasuk ibu hamil, untuk menghilangkan kecemasan mereka. Membaca atau mendengarkan AlQur'an merupakan adaptasi yang baik karena akan memberikan efek positif dengan memberikan harapan yang tak terbantahkan.

Dari segi fisiologis, ketika seseorang mendengarkan lagu pembacaan ayat suci Al-Qur'an dengan nada merdu, sinyal akan ditangkap oleh daun telinga, impuls akan ditransmisikan. talamus (batang otak). Jika seseorang memahami makna atau bahasa bacaan Al-Qur'an, impuls ditransmisikan ke area pendengaran primer dan sekunder, yang kemudian diproses di area wernicke untuk menafsirkan makna di dalamnya. area wernicke merupakan bagian dari otak manusia yang berada di bagian korteks otak besar dan mengelilingi korteks pendengaran. Pada area Wernicke impuls yang diterima pada otak akan diperdalam untuk menghasilkan makna, yang nantinya akan berperan dalam menentukan respon hipotalamus terhadap makna tersebut. Hasil respon tersebut, kemudian disimpan (dalam memori) serta dikirim ke amigdala untuk menentukan respons emosional (Suraga \& Aldama, 2014). Mendengarkan bacaan suci Al-Qur'an dengan makna yang terkandung di dalamnya akan memiliki efek positif pada respons emosional yang dikirim oleh amigdala, yang kemudian akan mengirimkan sinyal tersebut ke area otak. Hipotalamus sendiri berperan sangat penting dalam mengatur hormon yang mempengaruhi sistem imun tubuh. Selain hipotalamus, amigdala juga mengirimkan sinyal ke hipokampus untuk mengidentifikasi dan menyimpan respon tersebut. Hal ini akan ber- 
peran sangat penting dalam menentukan bentuk respon tubuh terhadap rangsangan yang ada (membaca Al-Qur'an) (Suraga \& Aldama, 2014).

Seorang tenaga kesehatan dengan beberapa latar belakang keperawatan, ia memiliki posisi kunci dalam membantu mengakomodasi kenyamanan kehamilan trimester kedua, terutama selama kehamilan, dengan mengurangi kecemasan yang terjadi selama kehamilan karena faktor internal dan eksternal ibu. Seorang perawat dalam membantu ibu hamil paruh waktu serta mengatasi persalinan akan berperan penting dalam menurunkan tingkat kecemasan ibu hamil.

\section{KESIMPULAN}

Penelitian ini membuktikan bahwa terapi murottal dengan aplikasi Spiritual Islamic Nursing Care (SINC) memiliki pengaruh terhadap respon denyut jantung janin (DJJ) dan tingkat kecemasan ibu hamil sedangkan tidak berpengaruh terhadap pergerakan janin. Terapi murottal dengan menggunakan aplikasi Spiritual Islamic Nursing Care (SINC) dapat diterapkan di tatanan pelayanan kesehatan, seperti praktik kebidanan, balai pengobatan rumah sakit bahkan dapat disosialisasikan kepada masyarakat luas. Aplikasi ini memiliki beberapa fitur yang dapat digunakan oleh pasien dalam pemenuhan kebutuhan spiritual dan agama khususnya bagi agama islam, Untuk peneliti lain, ini mungkin dapat menggunakan fitur yang lain seperti dzikir pagi petang, doa, tayammum dan wudhu, husnul khatimah care dan arah kiblat serta melibatkan lebih banyak responden serta penggunaan kelompok kontrol untuk menjaga keakuratan hasil.

\section{DAFTAR PUSTAKA}

Adhiwijaya, I. (2021). Murattal AlQur'anTherapy and Changes of Patient's Consciousness: A Literature Review. Psychology And Education, 58(1), 5309-5312. https://doi.org/10.17762/ pae.v58i1.1786

Azis, W., Nooryanto, M., \& Andarini, S. (2015). Terapi murottal Al-Qur'an Surat ArRahman Meningkatkan Beta Endorphin dan Menurunkan Intensitas Nyeri Bersalin Jurnal Kedokteran Brawijaya, 28(3). http:// dx.doi.org/10.21776/ub.jkb.2015.028.03.9

Brunton, R., Gosper, K., \& Dryer, R. (2021). Psychometric evaluation of the pregnancyrelated anxiety scale: Acceptance of pregnancy, avoidance, and worry about self subscales. Journal of Affective Disorders, 278 , 341-349. https://doi.org/10.1016/ j.jad.2020.09.064

Budiyarti, Y., \& Makiah. (2018). murottal Al Qur an Therapy Effect on Ansiety Level of Third Trimester Primigravida Pregnant Women. Jurnal Citra Keperawatan, 6(2), 89-99. http://ejurnal-citrakeperawatan.com/ index.php/JCK/article/view/88/

Cameron, E. E., Joyce, K. M., Delaquis, C. P., Reynolds, K., Protudjer, J., \& Roos, L. E. (2020) Maternal psychological distress \& mental health service use during the COVID-19 pandemic. Journal of affective disorders, 276, 765-774. https://doi.org/10.1016/ j.jad.2020.07.081

Dahro, A. (2012). Psikologi Kebidanan Analisis Perilaku Wanita Untuk Kesehatan. Jakarta: Salemba Medika.

Dinas Kesehatan Kota Makassar (2015). Profil Kesehatan Kota Makassar Tahun 2014.

Fatmawati, E. (2013). Perbedaan pengaruh pemberian stimulasi antara musik klasik dan murottal terhadap denyut jantung janin dan gerakan janin pada ibu hamil trimester ii serta iii (Doctoral dissertation, UNS (Sebelas Maret University). https:// digilib.uns.ac.id/dokumen/detail/30537

Ghofar, A., \& Ningsih, L. (2012). The Influences of 
Therapy and Music Therapy: Listening AlQur'an Juz Amma to Anxiety Responden at Toddler. Prosiding Seminar Competitive Advantage, $\quad$ 1(2). http:// www.journal.unipdu.ac.id/index.php/ seminas/article/view/152

Im-Oun, S., Kotruchin, P., Thinsug, P., Mitsungnern, T., Techa-Atik, P., \& Pongchaiyakul, C. (2018). Effect of Thai instrumental folk music on blood pressure: A randomized controlled trial in stage- 2 hypertensive patients. Complementary therapies in medicine, 39, 43-48. https:// doi.org/10.1016/j.ctim.2018.05.014

Irmawati, Hadju, V., Syamsuddin, S., \& Arundhana, A. I. (2020). The Effect of Listening to the Recitation of Qur'an ( murottal Ar-Rahman Surah) on the Level of Anxiety of Pregnant Women in Siti Fatimah Maternal and Child Hospital. Enfermeria Clinica, 30(2), 238242. j.enfcli.2019.07.097

Jabbari, B., Mirghafourvand, M., \& Mohammad, S. (2017). The Effect of Holy Quran Voice with and without Translation on Stress, Anxiety, and Depression During Pregnancy: A Randomized Controlled Trial. Journal of Tabriz University of Medical Sciences. https://doi.org/10.1007/s10943-0170417-x

Kader, M., \& Naim-Shuchana, S. (2014). Physical activity and exercise during pregnancy. The European Journal of Physiotherapy, 16(1), 2-9. https:// doi.org/10.3109/21679169.2013.861509

Kementerian Kesehatan RI. (2014). Profil Kesehatan Indonesia Tahun 2013. Jakarta

Kementerian Kesehatan RI. (2017). Profil Kesehatan Indonesia Tahun 2016. Jakarta.

Koelsch, S., \& Jäncke, L. (2015). Music and the heart. European heart journal, 36(44), 3043 -3049. https://doi.org/10.1093/eurheartj/ ehv430

Lawson, G. W., \& Keirse, M. J. (2013). Reflections on the maternal mortality millennium goal. Birth, 40(2), 96-102. https:// doi.org/10.1111/birt.12041

Lismayanti, L., Ariyanto, H., Azmi, A., Nigusyanti, A. F., \& Andira, R. A. (2021). Murattal AlQur'anTherapy to Reduce Anxiety among Operating Patients. Genius Journal, 2(1), 9-
15. http://genius.inspira.or.id/index.php/gj/ article/view/14

Liu, Y., \& Petrini, M. A. (2015). Effects of music therapy on pain, anxiety, and vital signs in patients after thoracic surgery. Complementary therapies in medicine, 23(5), 714-718. https:// doi.org/10.1016/j.ctim.2015.08.002

Mahjoob, M., Nejati, J., Hosseini, A., \& Bakhshani, N. M. (2016). The effect of Holy Quran voice on mental health. Journal of religion and health, 55(1), 38-42. https:// doi.org/10.1007/s10943-014-9821-7

May, L. E., Knowlton, J., Hanson, J., Suminski, R., Paynter, C., Fang, X., \& Gustafson, K. M. (2016). Effects of exercise during pregnancy on maternal heart rate and heart rate variability. $P M \& R, 8(7), 611-617$. https:// doi.org/10.1016/j.pmrj.2015.11.006

McLeish, J., \& Redshaw, M. (2017). Mothers' accounts of the impact on emotional wellbeing of organized peer support in pregnancy and early parenthood: a qualitative study. BMC pregnancy and childbirth, 17(1), 114. https://doi.org/10.1186/s12884-017$1220-0$

Melzer, K., Schutz, Y., Boulvain, M., \& Kayser, B. (2010). Physical activity and pregnancy. Sports Medicine, 40(6), 493-507. https://doi.org/10.2165/11532290000000000-00000

Mottaghi, M.E,., Esmaili, R., \& Rohani, Z. (2011). Effect of Quran recitation on the level of anxiety in athletics. Quran and Medicine, 2011, 1-4. https://darulquran.co.uk/wpcontent/uploads/2021/02/Effect-of-Quranrecitation-on-the-level-of-anxiety-inathletics.pdf

Mukhlis, H., \& Marini, M. (2020). Pengaruh terapi murottal terhadap denyut nadi dan pernafasan pada bayi dengan berat badan lahir rendah. Indonesia Berdaya, 1(1), 29-37. https://doi.org/10.47679/ib.202015

Nugroho, T., Nurrezki, Warnaliza, D., \& Wilis. (2014). Buku Ajar Asuhan Kebidanan Nifas. Yogyakarta: Nuha Medika.

Priyanto, P., Kamal, A. F., \& Dahlia, D. (2020). The Effectiveness of Psychoreligious Intervention: murottal Al-Qur'anon Pain and Stress Level of Bone Cancer Patient. Indonesian Journal of Global Health Research, 2(4), 
375-384.

https://doi.org/10.37287/

ijghr.v2i4.260

Ria, G., Maya, A., \& Jamalluddin, S. B. (2020). murottal Al-Qur'antherapy on decreasing labor pain and anxiety in maternity mothers first phase. Enfermeria clinica, 30, 110-114. https://doi.org/10.1016/j.enfcli.2019.11.034

Soma-Pillay, P., Nelson-Piercy, C., Tolppanen, H., \& Mebazaa, A. (2016). Physiological changes in pregnancy: review articles. Cardiovascular journal of Africa, 27 (2), 89-94. https://hdl.handle.net/10520/ EJC188686

Sugara, I. A. A., \& Mustofa, M. L. (2014). Efektivitas Pemberian Terapi Al-Qur'an terhadap Penurunan Kecemasan Ibu Hamil Primigravida Trimister III. Psikoislamika: Jurnal Psikologi dan Psikologi Islam, 11(2). https:// doi.org/10.18860/psi.v11i2.6386

Talbot, L., \& Maclennan, K. (2016). Physiology of pregnancy. Anaesthesia \& Intensive Care Medicine, 17(7), 341-345. https:// doi.org/10.1016/j.mpaic.2016.04.010

Thoma, M. V., Zemp, M., Kreienbühl, L., Hofer, D.,
Schmidlin, P. R., Attin, T., \& Nater, U. M (2015). Effects of music listening on pretreatment anxiety and stress levels in a dental hygiene recall population. International journal of behavioral medicine, 22(4), 498505. https://doi.org/10.1016/

j.ctim.2015.08.002

Veternik, M., Tonhajzerova, I., Misek, J., Jakusova, V., Hudeckova, H., \& Jakus, J. (2018). The impact of sound exposure on heart rate variability in adolescent students. Physiological research, 67(5), 695-702. https:// doi.org/10.33549/physiolres.933882

Wahyuni, R. \& Deswita. (2013). Pengaruh Terapi murottal Terhadap Tingkat Kecemasan Menghadapi Persalinan Pada Ibu Hamil di Wilayah Kerja Puskesmas Andalas. NERS Jurnal Keperawatan, 9(2), 116-126. https:// doi.org/10.25077/njk.9.2.116-126.2013

Zamriati, W. O., Hutagaol, E., \& Wowiling, F. (2013). Faktor-Faktor yang Berhubungan dengan kecemasan ibu hamil menjelang persalinan di Poli KIA PKM Tuminting. Jurnal Keperawatan, 1(1). https:// ejournal.unsrat.ac.id/index.php/jkp/article/ view/2249 